\title{
Research on Industry Situation Changes and Development Strategies of New Energy Automobile Companies
}

\author{
Chuiying Kong ${ }^{1, *}$, Feng Men ${ }^{1}$, and Tian Sun $^{1}$ \\ ${ }^{1}$ China Automotive Technology and Research Center Co.,ltd, 300300 No. 68, East Xianfeng Road, Dongli District, Tianjin, China
}

\begin{abstract}
This article sorts out the development of China's new energy vehicle industry from three levels of policy, market and technology, and judges the development trend. At the policy level, R\&D and innovation support policies, promotion fee policies, and going out policies will become development trends. At the market level, the future automobile market will gradually pick up and maintain a steady development trend. At the technical level, the level of three-electric technology and intelligent network technology will be further improved. On this basis, the company's development strategy is analyzed in order to provide a reference for the development of new energy automobile companies.
\end{abstract}

\section{The evolution of the new energy automobile industry}

\subsection{Policy evolution analysis}

According to the development stage of new energy vehicles, relevant industrial policies have roughly gone through three stages, namely the strategic planning period, the introduction period and the adjustment period.

2001-2008 is the strategic planning period. At this stage, relevant policies pay more attention to top-level design and provide strategic planning for the development of new energy vehicles. During this period, the focus was on technological innovation and production and sales, but the specific subsidy policy has not yet been reflected.

2009-2015 is the introduction period. During this period, the demonstration and promotion of new energy vehicles has become an important part of the policy. With the gradual improvement of strategic planning, policy coverage has become more extensive, involving R\&D subsidies, tax reductions and purchase subsidy, and increased support for infrastructure construction.

Since 2016, the new energy vehicle policy has entered an adjustment period. Compared with the strategic planning period and the introduction period policy, the adjustment period policy is more comprehensive and rigorous, and the content involves safety supervision, infrastructure construction and other aspects[1]. In terms of new energy vehicle technology and component performance, standards have been set higher, more stringent regulatory measures have been formulated for fraudulent compensation.

\subsection{Market evolution analysis}

The development of China's automobile industry has been through more than 60 years. Generally speaking, it can be roughly divided into three stages. 2000-2010 is the golden development period of China's automobile industry, with a rapid growth rate of $25 \%$ on average. After 2010, the growth rate of automobile production and sales began to decline, China's auto industry has entered a single-digit growth period; China's auto sales fell for the first time in 2018, marking a new stage in the development of auto industry.

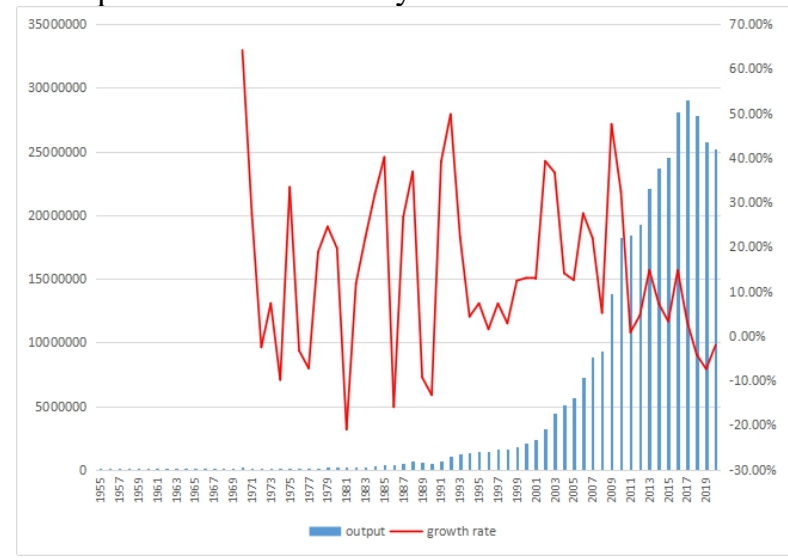

Fig. 1.The development history of the automotive industry

The development of China's new energy automobile industry began in the 1990s, and has gone through four stages: R\&D layout, industrialization preparation, demonstration and promotion, and industrialization development. 1991-2005 was the stage of R\&D deployment, and new energy vehicle related technologies were included in the national major scientific and technological research. From 2006 to 2010,

* Corresponding author: kongchuiying@catarc.ac.cn 
as the preparation stage for industrialization, the state launched small-scale demonstration applications of electric vehicles. 2011-2015 is the stage of demonstration and promotion. In 2015, China's production and sales of new energy vehicles ranked first in the world. Since 2016, China's new energy vehicles have begun to enter the stage of industrialization development, initially achieving large-scale applications, and ranking first in global sales for five consecutive years.

\subsection{Technology evolution analysis}

\subsubsection{Analysis of the evolution of power battery technology}

The development of power batteries has roughly gone through three stages. Lithium cobalt oxide batteries are the first generation of batteries used in the field of electric vehicles. Although its industry is mature and has experience in the digital field, it has shortcomings such as high manufacturing cost, fewer cycles of charging and discharging, and poor safety performance, it is gradually abandoned.

Lithium manganese oxide and lithium iron phosphate batteries are second-generation power batteries. Lithium iron phosphate is a power battery widely used in new energy vehicles, but it also has certain defects. The battery pack ability is poor, and is easy to form lithium dendrites at low temperatures, which affects the safe driving of electric vehicles, and its low tap density results in large product volume[2].

The third-generation power battery is represented by the ternary material battery. With the breakthrough of the ternary material battery technology, its safety performance has been improved. The national policy level also holds a more positive attitude towards this type of battery. The ternary material battery gradually become the mainstream trend of the pure electric vehicle battery market.

\subsubsection{Analysis of the evolution of drive motor technology}

New energy vehicles use electric motors instead of traditional internal combustion engines as power output components. As new energy vehicles have higher performance requirements for drive motors such as wide speed range, high power density, and high efficiency. Permanent magnet synchronous motor technology gradually replaces traditional DC motor and induction motor drive technology, and become the mainstream drive motor solution for new energy vehicles. However, with the continuous improvement of drive motor power density and efficiency, permanent magnet synchronous motors manufactured with traditional structures and traditional processes are gradually unable to meet the current market competition needs. Major traditional OEMs and emerging car manufacturers urgently need to find new technologies solution.

\section{Development trend of new energy vehicles}

\subsection{Policy trends}

2020 is a critical period for China's new energy automobile industry policy to inherit the past and the future. The relevant departments continue the previous framework system and dynamically adjust according to the actual situation. In recent years, due to trade frictions, DE-globalization and the new crown epidemic, market uncertainty has increased. In the face of fierce international competition and a complex domestic market environment, in the future, relevant policies will be further strengthened in the process of industrial development. R\&D and innovation support policies, promotion fee policies, and going global policies will become development trends.

Reducing enterprise R\&D costs and maintaining enterprise innovation vitality are important points for enhancing competitiveness. Under the strategic orientation, it will focus on innovation support for new technologies, new models, and new business formats. While implementing an inclusive and prudent industry management policy, accelerating the transformation of industry support policies to competitive policies, and accelerating the improvement of the competitiveness of enterprises and products by guiding and strengthening market competition.

At the level of automobile consumption, the current growth rate of China's automobile market is slowing down[3]. Further analysis of market demand, in-depth explore of consumption potential, and search for new growth points are the direction of policy reform and innovation.

Under the background of economic globalization, the epidemic has blocked the global flow of production factors. As the epidemic is gradually controlled and international competition is back on track, the policy level will guide companies to plan ahead, give full play to multilateral cooperation and high-level dialogue mechanisms, and establish an inter-governmental strategic partnership for new energy vehicles, actively participate in the formulation of international economic, trade and investment rules, and form an open, transparent and inclusive multilateral trading system in the field of new energy vehicles. Encourage enterprises to go global, achieve all-round international development in technology, products, brands, etc., and deeply integrate into the global supply and marketing system.

\subsection{Market trend}

In recent years, the promotion of new energy vehicles has continued to strengthen, and favorable policies have continued to drive the rapid growth of the domestic market. The market base is gradually expanding and the market share has increased year by year, occupying a leading position in the world's new energy industry. In 2019 , due to the decline in subsidies and the downturn in 
the industry development environment, the growth of the new energy market has begun to weaken. Since July 2019, it has shown a downward trend and continues to the present. The competition mechanism of the new energy market has gradually become marketer. The shift from policy-driven to market-driven, the market will resume steady growth. In the future, from the perspective of policy environment, demand side, supply side and supporting facilities, new energy vehicle market will gradually pick up and maintain a steady development trend.

In terms of policy environment, China has issued an industrial development plan to clarify goals. New energy vehicles are still the general trend. Supporting policies are gradually shifting to non-financial and tax subsidies. Policies such as double points, product access and battery specifications have become the focus, Gradually formed a long-term support mechanism for new energy vehicles.

In terms of demand, users' satisfaction with the product has increased. With the clear market positioning of enterprises, the launch of high-quality products, and with the development of the new energy vehicle market, consumers' acceptance and awareness of new energy have gradually increased.

In terms of supply, foreign-funded enterprises increase their investment in electrification, which will further stimulate the vitality of domestic competition. At the same time, new energy products will achieve both quality and quantity improvements to meet the diverse needs of consumers. But the current battery technology has shortcomings, moreover, the irrational pursuit of cruising range and energy density will exacerbate potential safety hazards in the new energy industry and reduce consumers' recognition of new energy.

In terms of supporting facilities, with the support of new infrastructure, development planning and other policies, the construction of charging infrastructure will be further accelerated to support the high-quality development of the new energy automobile industry. However, the distribution of charging piles is uneven, private piles are difficult to enter the community, the low utilization rate of public piles is still common, which will affect consumers' decision to purchase new energy vehicles and restrict the development of the industry to a certain extent.

In the future, as the overall macro level picks up moderately, the new energy market will gradually pick up[4]. In the medium and long term, on the one hand, new energy development plans and double points support the high-quality development of new energy. On the other hand, with the improvement of key technologies and the gradual enhancement of consumer awareness of new energy in the future, the market may continue to grow. .

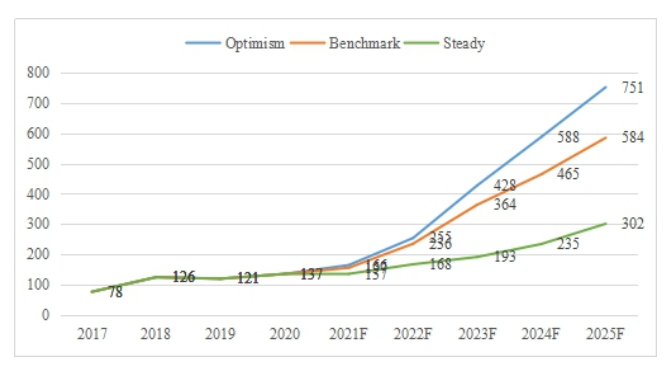

Fig. 2.Trend forecast of China's new energy vehicle market from 2021 to 2025 (unit: ten thousand vehicles)

\subsection{Technology trends}

New energy vehicles are the inevitable trend of the future development of the automobile industry. As the core technology of new energy vehicles, the development of battery, motor, electronic control technology has received the attention of the industry. The drive motor is the direct power device for driving vehicles. Motor technology represented by permanent magnet synchronous motors and in-wheel motors has significantly improved performance and comfort, which has increased the acceptance and penetration of new energy vehicles. The development of core technologies surrounding the permanent magnetization of motors, the integration of motor drive systems, and the integration and digitization of motor control have become research hotpots at home and abroad.

Power battery technology is the most important and competitive core technology for new energy vehicles. The current trend of power battery technology route is lithium iron phosphate $\rightarrow$ ternary lithium $\rightarrow$ solid state battery. If you want to achieve higher energy density in the future, you need to switch to a solid-state battery technology system. At the same time, wireless charging and battery swapping technology can break the limitations of charging in time and space, greatly improve charging efficiency, and solve charging problems. The development of the above technologies will become the future battery development trend.

Compared with internal combustion engines, the motors on new energy vehicles can almost achieve instantaneous response to commands and are more suitable for intelligent development[5]. The processed signal is an electrical signal, which is more adaptable to the theory of smart cars in terms of speed and control difficulty. New energy vehicles integrate advanced material technology and high-precision component manufacturing technology in electrification, and are more adaptable and compatible with the new generation of electrical and electronic architecture, and are an important carrier for the application of intelligent technology. The realization of higher-level autonomous driving functions in the future will bring revolutionary changes to the development of the new energy automobile industry. The core technologies and products of smart cars, such as sensors, computing platforms, high-precision maps, and wire-controlled actuators, will achieve rapid development. Together with motors, batteries, and electronic controls, they will become the 
core of the new energy automotive industry chain in the future.

\section{Development strategy of new energy vehicle companies}

\subsection{Keep up with national policies, adjust strategy timely}

In October 2020, the General Office of the State Council issued the "New Energy Automobile Industry Development Plan (2021-2035)", which aims to promote the high-quality development of the new energy automobile industry and accelerate the establishment of a powerful automobile country. The plan clearly states that "By 2025, China's new energy vehicle market will be significantly more competitive. Major breakthroughs were made in key technologies such as power batteries, drive motors, and vehicle operating systems, and the safety level was comprehensively improved. "Strive to achieve the international advanced level in the core technology of China's new energy vehicles after 15 years of continuous efforts, and the quality brand has strong international competitiveness. "In response to the strategic vision proposed in the plan, new energy vehicle companies need to deepen their efforts in technological innovation and "stuck neck" technical research, gradually improve software and hardware research and development capabilities, and focus on short-board weaknesses such as core processes and key components. Actively exploring different technological paths to effectively improve the level of $R \& D$ technology.

\subsection{Increase R\&D investment, master key technologies}

With the removal of restrictions on foreign shareholding in new energy automobile companies and Tesla, BMW, etc. invested in the production of new energy vehicles in China, China has gradually become an important market for global new energy vehicle companies to compete. Improving core innovation capabilities has become the key for new energy vehicle companies to obtain core competitiveness and promote their leap to the high end of the global value chain. In practice, innovation is a continuous and dynamic process, depending on how much new energy vehicle companies invest in R\&D.

Facing the new industry development environment, companies should increase $R \& D$ investment, focus on the training and introduction of internal high-end R\&D talents, strengthen cooperation with external professional research institutions, and improve their own R\&D capabilities, master the core technology of new energy vehicles, build a professional $R \& D$ platform, improve the reliability, safety, driving speed, cruising range and other key indicators of new energy vehicles, reduce the production cost of key components such as batteries and motors, and earnestly master the core key technologies.

\subsection{Build financing channels, pay attention to investment management}

In the current downturn in the development of the automobile market, building corresponding financing channels is the main way for new energy automobile companies to survive and continue to develop. From the perspective of vehicle manufacturers, based on the characteristics of large demand for fixed assets and high production expectations, it is necessary to build diversified financing channels and pay attention to investment management. In the process of investment project management, it should pay attention to the specific process of investment management, focus on strengthening the standardization, rationality and rigor of the investment management process, and improve the quality and efficiency of investment management. During the investment process, external financial experts can be hired to analyze the financial feasibility of the investment project to provide favorable support for project investment decision-making.

\section{Conclusions}

Through research on new energy vehicle policy, market and technological evolution, it is found that China's new energy vehicle policy and market have gone through three stages with the development of the industry. At the technical level, battery and motor technologies are making rapid progress under the pressure of market demand and corporate competition. On the development trend of new energy vehicles, at the policy level, R\&D and innovation support policies, promotional fee policies, and going global policies will become development trends; at the market level, the future automotive market will gradually pick up and maintain a steady development trend; At the technical level, the level of three-electric technology and intelligent network technology will be further improved.For enterprise development, it is necessary to closely follow national policies, adjust strategies in due course, increase R\&D investment, master key technologies, build financing channels, and attach importance to investment management.

\section{References}

1. Lee S, Kim Y, Chong W K. A Statistical Analysis of Effectiveness of Energy Policy in the United States: Incentives vs. Regulations[J]. Procedia Engineering, 2015, 118:1282-1287.

2. Lévay, Petra Zsuzsa, Drossinos Y, Thiel C. The effect of fiscal incentives on market penetration of electric vehicles: A pairwise comparison of total cost of ownership[J]. Energy Policy, 2017, 105:524533.

3. Lieven T. Policy measures to promote electric mobility - A global perspective[J]. Transportation Research Part A, 2015, 82:78-93.

4. Manzetti S, Mariasiu F. Electric vehicle battery technologies: From present state to future systems[J]. 
Renewable and Sustainable Energy Reviews, 2015, 51:1004-1012.

5. Marimuthu K P, Durairaj D, Karthik Srinivasan S. Development and implementation of advanced metering infrastructure for efficient energy utilization in smart grid environment[J]. International Transactions on Electrical Energy Systems, 2017:e2504. 